\title{
Latihan Endurance Penderita Pasca Stroke Iskemik
}

\author{
${ }^{1}$ Novi Putri Amalia, ${ }^{2}$ Moch. Ichwanul Rahman \\ Program Studi,Fisioterapi Fakultas Vokasi, Universitas Airlangga \\ Jl. Dharmawangsa Dalam Selatan No.28 - 30, Airlangga, Kec. Gubeng, Kota SBY, Jawa Timur \\ 60286 \\ Email : ichwanerahman@gmail.com
}

Tanggal Submisi : 4 Mei 2021 ; Tanggal Penerimaan: 3 Desember 2021

\begin{abstract}
ABSTRAK
Stroke Menurut World Health Organization adalah adanya tanda- tanda klinik yang berkembang cepat akibat gangguan fungsi otak fokal (global) dengan gejala-gejala yang berlangsung selama 24 jam atau lebih yang menyebabkan kematian tanpa adanya penyebab lain yang jelas selain. Salah satu gejala sisa dari stroke yaitu menurunnya kualitas hidup. Bentuk aktifitas yang harus dilakukan oleh penderita pasca stroke untuk melakukan kegiatan sehari-hari seperti sebelum terkena stroke adalah mengembalikan kebugaran tubuh.Kebugaran untuk penderita pasca stroke dapat dicapai dengan latihan endurance, khususnya latihan-latihan yang bersifat aerobik secara rutin dan terkontrol dengan dosis yang tepat, dengan menggunakan alat maupun tanpa alat seperti senam, bersepeda, berjalan, cycling cycle, recumbent, dan treadmill. Salah satu tolak ukur yang paling sering digunakan untuk mengetahui kebugaran fisik seseorang adalah konsumsi oksigen maksimal $\left(\mathrm{VO}_{2}\right.$ max $)$.
\end{abstract}

Kata kunci: stroke, latihan endurance, $\mathrm{VO}_{2}$ max

\begin{abstract}
According to World Health Organization, stroke is the presence of rapidly developing clinical sign due to fokal (global) brain functional disorders with symptoms for 24 hours or more that cause death without any other obvious cause other than vascular. One of the other symptomps is a decrease in quality of life. The activities that must do for patient after stroke in daily actvities such as before stroke is return the body fitness.Fitness patient with post stroke can be achieved through a variety of endurance exercise, especially exercise that are aerobic routine and controlled with the right dose, such as gymnastic, cycling cycle, recumbent, and treadmill. One of the most frequently used to determine physical fitness is maximum oxygen consumption $\left(\mathrm{VO}_{2} \max \right)$.
\end{abstract}

Keywords: stroke, endurance exercise, $\mathrm{VO}_{2} \max$

ISSN 2722-9610

E - ISSN 2722-9629

\section{Pendahuluan}

Stroke adalah suatu kondisi yang terjadi ketika pasokan darah ke suatu bagian otak tibatiba terganggu, karena sebagian sel-sel otak mengalami kematian akibat gangguan aliran darah yang disebabkan sumbatan atau pecahnya pembuluh darah otak. Dalam jaringan otak, kurangnya aliran darah menyebab kan serangkaian reaksi biokimia yang dapat merusakan atau mematikan sel-sel saraf otak. 
Kematian jaringan otak dapat menyebabkan hilangnya fungsi yang dikendalikan oleh jaringan itu. Aliran darah yang berhenti membuat suplai oksigen dan zat makanan ke otak berhenti, sehingga sebagian otak tidak bisa berfungsi sebagaimana mestinya (Nabyl, 2012). Stroke Menurut WHO adalah adanya tanda-tanda klinik yang berkembang cepat akibat gangguan fungsi otak fokal (global) dengan gejala-gejala yang berlangsung selama 24 jam atau lebih yang menyebabkan kematian tanpa adanya penyebab lain yang jelas selain vaskuler (Mujahidullah, 2012). Stroke umumnya merupakan penyebab kematian nomor 2 di dunia, setelah penyakit jantung iskemik. Sedangkan di negara Indonesia sendiri menjadi penyebab kematian yang utama, sebanyak $21,1 \%$ orang meninggal setiap tahunnya (Balitbangkes Kemenkes RI, 2014). Kasus terbanyak pada kasus stroke adalah $80 \%$ stroke iskemik. Stroke iskemik adalah tanda klinis disfungsi atau kerusakan jaringan otak yang disebabkan kurangnya aliran darah ke otak sehingga mengganggu kebutuhan darah dan oksigen di jaringan otak (Caplan,2003).

Penderita stroke akan mengalami banyak gangguan yang bersifat fungsional. Gejala stroke dapat bersifat fisik, psikologis, dan perilaku. Gejala dan tanda dari stroke tergantung pada daerah mana yang mengalami kerusakan di otak. Secara umum tanda dan gejala stroke diantaranya: munculnya kelemahan mendadak dari salah satu bagian tubuh seperti wajah, lengan, dan tungkai, serta muncul rasa hilangnya sensasi mendadak di satu sisi badan, gangguan menelan (disfagia), hilangnya penglihatan sebagian atau menyeluruh secara tiba-tiba, sulit bicara (pelo) atau tidak memahami pembicaraan orang lain (afasia), timbul nyeri kepala yang amat sangat maupun mendadak, gangguan kesadaran, hilangnya keseimbangan, maupun munculnya gangguan kognitif (WHO, 2015).

Kebugaran untuk penderita pasca stroke dapat dicapai melalu berbagai latihan, khususnya latihan-latihan yang bersifat aerobik secara rutin dan terkontrol dengan dosis yang tepat, dengan menggunakan alat maupun tanpa alat seperti senam, bersepeda, berjalan, cycling cycle, recumbent, dan treadmill. Menurut, Soegiarto (2004) mengungkapkan bahwa latihan fisik selain bermanfaat untuk kebugaran tubuh, juga bermanfaat untuk menstabilkan fungsi sistem organ manusia. Latihan fisik juga memainkan peran penting dalam pemeliharaan fungsi otot dalam tubuh manusia (Berwald, 2007).

Salah satu tolak ukur yang paling sering digunakan untuk mengetahui kebugaran fisik seseorang adalah konsumsi oksigen maksimal $\left(\mathrm{VO}_{2}\right.$ max $)$. Pada penderita pasca stroke akan terjadi penurunan dari kapasitas kardiorespirasi yang akan mempengaruhi $\mathrm{VO}_{2}$ max. Apabila latihan tersebut dilakukan secara rutin diharapkan daya tahan kardiorespirasi penderita akan selalu terkontrol dan optimal dalam melakukan aktifitas sehari-hari tanpa adanya keluhan guna meningkatkan VO2 max (Moore, 2013).

Berbagai literatur yang peneliti dapatkan memperlihatkan bahwa aktifitas/latihan fisik yang dilakukan secara teratur mampu memperbaiki kemampuan fungsional pasien pasca stroke. Penelitian yang dilakukan oleh Bilinger (2014) menemukan bukti bahwa pada penderita pasca stroke dapat diberi latihan fisik seperti latihan aerobik dengan intensitas sedang dan rendah, serta latihan penguatan otot yang bertujuan untuk mencegah terjadinya stroke sekunder. Menurut David (2017) latihan aerobik menggunakan alat recumbent steps dengan metode submaksimal dapat berpengaruh positif pada orang dewasa sehat maupun penderita stoke.

\section{Metode Penelitian}

Penelitian yang dilakukan oleh Duncan (2003) disebutkan latihan dengan static cycle akan meningkatkan ambilan oksigen pada responden post stroke jika latihan dilakukan 3-4 kali seminggu secara berturut-turut selama 8 kali pengulangan 
dengan intensitas waktu 10-30 menit. Secara anatomis tubuh akan membiasakan dengan latihanlatihan fisik yang bersifat terprogram sehingga akan mudah tubuh mengolah asupan- asupan baru yang masuk dalam tubuh termasuk latihan kardiovaskular. Metabolisme tubuh akan memerlukan oksigen untuk mengubah energi makanan menjadi ATP (Adenosine Triphosphate) untuk kerja tiap sel sehingga kebugaran tubuh akan terjaga dengan baik.

\section{Hasil}

Pasien bernama Tn. M berusia 70 tahun dengan diagnosa post hemiparese sinistra ec stroke infark $1^{\text {st }}$ attack (2th) + DM + HT. Keluhan utama pasien berupa mudah lelah saat melakukan aktifitas dan masih ada kelemahan pada anggota gerak atas dan bawah bagian kiri. Didapatkan problem kapasitas fisik berupa penurunan kekuatan otot AGA dan AGB sinista, hamstring tighness pada AGB sinistra, keterbatasan luas gerak sendi AGA dan AGB sinistra, penurunan kapasitas vital paru, penurunan ekspansi thoraks, dan penurunan daya tahan kardiovaskular serta problem kemampuan fungsional berupa Pasien kesulitan atau memerlukan bantuan saat naik turun tangga secara mandiri karena pasien belum mampu single leg stand pada AGB sinistra dan pasien mudah lelah saat berjalan sejauh $>500 \mathrm{~m}$. Pasien mendapat tindakan fisioterapi sebanyak 6 kali berupa latihan komponen pendukung postural dengan inhibisi spastik, latihan penguatan otot dorso flexor AGB sinistra, serta latihan pendukung endurance berupa deep breathing exercise, mobilisasi sangkar thoraks dan latihan utama endurance berupa latihan menggunakan static cycle, latihan menggunakan recumbent, latihan dengan berjalan. Hasil yang didapat setelah latihan selama 6 kali terapi dengan fokus latihan daya tahan kardiovaskular (endurance) yaitu peningkatan METs dari 2,85 METs menjadi 4,21 METs .

\section{Pembahasan}

Pasca stroke 3 tahun yang lalu pasien mulai merasakan penurunan toleransi aktivitas seharihari (endurance), terutama melakukan aktivitas dengan intensitas yang lama dan mengangkat beban berat. Selain terjadi penurunan toleransi aktivitas sehari-hari, pasien juga mengalami problem kapasitas fisik berupa penurunan kekuatan otot AGA dan AGB sinista, hamstring tighness pada AGB sinistra, keterbatasan luas gerak sendi AGA dan AGB sinistra, penurunan kapasitas vital paru, penurunan ekspansi thoraks, dan penurunan daya tahan kardiovaskular. Didapatkan juga problem kapasitas fungsional berupa pasien kesulitan atau memerlukan bantuan saat naik turun tangga secara mandiri karena pasien belum mampu single leg stand pada AGB sinistra dan pasien mudah lelah saat berjalan sejauh $>500 \mathrm{~m}$.

Dari problem kapasitas fisik dan kemampuan fungsional diatas dilakukan tindakan fisioterapi sebanyak enam kali pertemuan 18-032019. 19-03-2019, 21-03-2019, 25-03-2019, 2703-2019, 29-03-2019. Diberikan latihan pendukung berupa positioning / inhibisi spastik elbow flexor sinistra, latihan penguatan otot dorso flexor AGB sinistra, dan latihan fokus daya tahan kardiovaskular berupa deep breathing exercise, mobilisasi sangkar thoraks, latihan endurance berupa latihan menggunakan static cycle, latihan menggunakan recumbent, dan latihan berjalan.

Berdasarkan penilaian Six Minute Walking Test (6MWT) pada saat pertama perlakuan, pasien hanya berjalan sejauh 180 meter dengan hasil 2,85 METs. Dari hasil tersebut dapat disimpulkan bahwa hasil dibawah rata-rata berdasarkan data kategori kebugaran jasmani berdasarkan umur dewasa tua 70-79 dengan jarak tempuh sejauh $527 \pm 85 \mathrm{~m}$ (Steffen et al., 2002). Setelah dilakukan latihan endurance pasien mengalami peningkatan METs dari 2,85 METs menjadi 4,21 METs, peningkatan SpO2 dari 95\% menjadi $97 \%$ dan peningkatan jarak tempuh dari 
$180 \mathrm{~m}$ menjadi $260 \mathrm{~m}$. Hal tersebut menunjukkan peningkatan dari daya tahan kardiovaskular (endurance).

Kadar maksimal konsumsi oksigen $\left(\mathrm{VO}_{2}\right.$ max) merupakan indikator utama dari daya tahan kardiovaskular yang menggambarkan kemampuan maksimum tubuh untuk mengolah oksigen. Pada 6MWT peningkatan $\mathrm{VO}_{2}$ max dapat ditunjukan dengan jarak berjalan yang ditempuh dalam waktu 6 menit. Semakin jauh jarak yang ditempuh maka semakin tinggi jumlah maksimal oksigen yang dibutuhkan. Peningkatan $\mathrm{VO}_{2}$ max menunjukkan semakin tinggi toleransi aktvitas yang dapat dilakukan. Dari hasil evaluasi menunjukkan perubahan yang terjadi yaitu peningkatan jarak dari hasil 6MWT yang dapat diartikan sebagai peningkatan toleransi aktivitas. Program latihan dapat memberikan efek pada sistem kardiovaskular, respirasi, dan otot.

\section{Kesimpulan dan Saran}

Kondisi fisik setelah mengalami stroke menyebabkan berbagai masalah akibat gejala sisa dari fungsi otak yang tidak membaik sepenuhnya. Beraktivitas secara mandiri dan optimal adalah tujuan utama penderita pasca stroke. Salah satu bentuk aktifitas yang harus dilakukan oleh penderita pasca stroke untuk melakukan kegiatan sehari-hari seperti sebelum terkena stroke adalah mengembalikan kebugaran tubuh dengan latihan endurance.

Setelah dilakukan tindakan fisioterapi berupa latihan endurance selama enam kali terapi, evaluasi yang didapatkan yaitu meningkatanya jarak yang ditempuh pasien saat dilakukan tes 6MWT, peningkatan tersebut menunjukkan peningkatan $\mathrm{VO}_{2}$ max dan peningkatan METs yang menggambarkan ada peningkatan daya tahan kardiovaskular (endurance).

Bagi pasien, untuk memperoleh hasil terapi yang optimal dilakukan kerjasama yang baik antara pasien, keluarga pasien dan terapis serta tim medis yang terkait sehingga memungkinkan didapatkan hasil yang maksimal.

\section{Daftar Pustaka}

Ambrosini, E. et al. 2012. Cycling induced by electrical stimulation improves muscle activation and symmetry during pedaling in hemiparetic patients. IEEE Trans Neural Syst Rehabil Eng. 20:320-330.

American Thoracic Sosiety. 2002. ATS Statement : Guideline for Six Minute Walking Test. American Journal of Respiratory and Critical Medicine. Vol 166.

American College of Sports Medicine. 2015. ACSM'S Guidelines for Exercise Testing and Prescription. 9th edition. Philadelphia. Lippincolt Williams \& Wilkins:186-191.

Barbosa, D., C. P. Santos, and M. Martins. The application of cycling and cycling combined with feedback in the rehabilitation of stroke patients: a review. J. Stroke Cerebrovasc. 24:253-273, 2015.

Bompa, T.O. (2000). Theory and Methodology of Training. IOWA: Kendaii Hunt Pub. Company.

Burke RE. 2001. Panduan lengkap latihan kebugaran (fitnes Dirumah). Jakarta.

Burke RE. 2001. Panduan lengkap latihan kebugaran (fitnes Dirumah). Jakarta.

Chusid, J.G. 1983. Neuroanatomi Korelatif dan Neurologi Fungsional. Penerbit Gadjah Mada University Press. Yogyakarta.

Classen J, Knorr U, Werhahn KJ, Schlaug G, Kunesch E, Cohen LG, Seitz RJ, Benecke R. Multimodal output mapping of human central motor representation on different spatial scales. J Physiol. 1998;512(Pt 1):163-79. 
Djoko P.I. (2000). Panduan Latihan Kebugaran

(Yang Efektif dan Aman). Yogyakarta:

Lukman Offset.

Doewes Muchsin dkk. 2011. Kontribusi Sistem Respirasi Terhadap VO2 Maks: Studi Korelasional Pada Atlet Berbagai Cabang Olahraga Di Surakarta. J Respir Indo Vol. 31, No. 1.

Duncan, P. Studenski, S, Richards, L, Gollub, S, Lai, SM, Reker, D, Perera, S, Yates J, Koch,V, \& Rigler S. 2003. Randomized clinical trial of therapeutic exercise in subacut stroke. Stroke . 34(9):2173-218.

Egger, G. (1993). The Fitness Leader's Exercise Bible. NSW: Kangooroo Press Pty. Ltd

Feigin. V. 2006. Stroke. Jakarta: PT Buana Ilmu Populer.

Fox SI. Muscle. 2003. Mechanism of Contraction and Neural Control. In : Fox SI. Human Physiology, 8nd ed. Kota : McGraw-Hill.

Ganong, W.L. (1995). Buku Ajar Fisiologi Kedokteran. Alih bahasa oleh Djauhari Widjayakusumah, dkk. Jakarta: Peneribit Buku Kedokteran EGC.

Hinson C. (1995). FITNESS For Children. Leeds. England: Human Kinetics.

Huang, H. J., \& Ferris, D. P. (2004). Neural coupling between upper and lower limbs during recumbent stepping. Journal of Applied Physiology, 97(4), 1299-1308.

Hudaya, Prasetya. 2002. Dokumentasi Persiapan Praktek Profesional Fisioterapi (DP3FT). Surakarta. Politeknik Kesehatan Surakarta Jurusan Fisioterapi.

Irfan, Muhammad. 2012. Fisioterapi bagi Insan Stroke. GrahaIlmu, Jakarta.

Janssen P.GJM. (1989). Training Lactate PulseRate. New York: Polar Electro of
Publishing.

Junaidi, Iskandar, 2006; Stroke A-Z, PT Buana Ilmu Popular, Jakarta.

Kinetic Pub : 16 \& 23.

Kisner, Carolyn dan Lynn Allen Colby. 2007. Therapeutic Exercise: Foundations and Techniques 5th edition. Philadelpia, USA:

F.A. Davis Company.

Leon, AS. 2007. Physical Activity \& Cardiovascular Health. Champaign : Human

Moore, E,Agur R \& Moore, L.2013. Anatomi Berorientasi Klinis 5th ed.dialih oleh hartanto H. Jakarta: Erlangga.

Naufal, A. F., Fatmarizka, T., Rahayu, U. B., Nafi'ah, D., Latifah, Y., \& Astari, R. W. (2021). Relationship between flat foot and lower limb muscle activation among 12 years old children. Journal of Medicinal and Chemical Sciences, 4(4), 381-387. https://doi.org/10.26655/JMCHEMSCI.202 1.4 .9

Netter et al. 2002.Atlas of Neuroanatomy and Neurophysiology.Teterboro, New Jersey: Icon Custom Communication.

Nossek J. (1992). Predicting the Oxygen Cost Of Air Breaked Ergometri. Research Quartely for Exer. And Sport. Vol 3

Nudo RJ, Milliken GW, Jenkins WM, Merzenich MM. Use-dependent alterations of movement representations in primary motor cortex of adult squirrel monkeys. $\mathrm{J}$ Neurosci. 1996;16(2):785-807

Palmer-McLean, K., \& Harbst, K. B. (2003). Stroke and Brain Injury. In J.

L. Durstine, Moore, G.E. (Ed.), ACSM's Exercise Management for Persons with Chronic Diseases and Disabilities (pg. 238- 246): Human Kinetics 
Pate R, Me. Clengham B, Rotella R. (1984). Scientific Foundation of Coaching. Philadelphia: Saunders College Publishing.

Rushall B.S, Pyke, F.S. (1990). Training for Sport and Fitness. Melbourne: MacMilan Co.

Sharkey BJ. (1984). Physiology of Fitness. Illionis: Human Kinetics Publishing.

Sherwood L, (2013). Fisiologi Manusia dari Sel ke Sistem, alih bahasa Brahm U. Pendit.Jakarta: Penerbit Buku Kedokteran EGC
Stoloff, R., Zehr, E., \& Ferris, D. (2007). Recumbent stepping has similar but simpler neural control compared to walking. Experimental brain research, 178(4), 427-438.

Suyono, A., 1992; Gangguan Sensori Motor pada Penderita Hemiplegi Pasca Stroke, Workshop Fisioterapi pada Stroke, IKAFI Jakarta. 